\title{
La izquierda se toma la universidad. La protesta universitaria en Colombia durante los años sesenta
}

\author{
The left and the university. The university protest in Colombia \\ during the sixties
}

Edwin Cruz Rodríguez ${ }^{*}$

Resumen: Este trabajo ofrece un análisis sintético de la protesta universitaria en Colombia durante los años sesenta, desde la perspectiva de la teoría del proceso político. El auge de la protesta se explica principalmente por la influencia de las distintas expresiones de la izquierda, pues sus formas organizativas y sus marcos discursivos permitieron articular a los estudiantes entre sí y con otros sectores populares, para enfrentar un contexto político con pocas oportunidades políticas, configurado por el sistema político del Frente Nacional que respondía predominantemente a los intereses de los partidos tradicionales y de sus clientelas políticas, se encontraba cerrado frente a las demandas de los sectores sociales emergentes producto de los procesos de modernización y respondió a la protesta social con aterradores niveles de represión que rayan con el terrorismo de Estado.

Palabras clave: Colombia, izquierda, protesta universitaria, movimiento estudiantil, años sesenta.

\begin{abstract}
This paper makes a synthetic analysis of university protest in Colombia during the sixties from the perspective of the theory of political process. The rise of the protest is mainly explained by the influence of the different expressions of the left. Their organizational forms and discursive frameworks allowed students articulate with each other and with other popular sectors to face a political context with few opportunities policies. the political system of the National Front responded mainly to the interests of the traditional parties and their political clientele. Therefore, it was closed against the demands of emerging social sectors product of the processes of modernization and responded to social protest with frightening levels of repression verging with state terrorism.
\end{abstract}

Key words: Colombia, left, University protest, student movement, sixties

Recibido: 11 marzo 2016

Aceptado: 5 mayo 2016

* Colombiano, Politólogo, profesor en el Departamento de Ciencia Política de la Universidad Nacional de Colombia sede Bogotá, ecruzr@unal.edu.co 


\section{Introducción}

Durante los años sesenta Colombia se vio enfrentada a las tensiones propias de una sociedad en camino de modernización, la cual se expresó en tres procesos que estuvieron en la base de la conflictividad social de la época: el retorno a la democracia luego del breve período de dictadura (1953-1957) instaurada bajo la anuencia de los partidos tradicionales, Liberal y Conservador, para poner fin a la violencia entre ellos (Valenzuela, 2012); la transición hacia un Estado interventor, que desde entonces y hasta mediados de los años setenta se convierte en el actor central del desarrollo y la industrialización (Lucio y Serrano, 1992: 51); y una transformación societal, que comprende una oleada de migraciones campo-ciudad como resultado de la cual emergen demandas de sectores medios urbanos por participación política y servicios sociales (Leal y Dávila, 1991).

La protesta estudiantil será protagonista en el marco del auge de la "nueva izquierda" (Archila y Cote, 2009) y sobre todo de la revolución cubana, que paulatinamente aleja el estudiantado de los partidos tradicionales (Leal, 1984). Aunque la historiografía sobre el movimiento estudiantil presenta considerables avances en cuanto a la reconstrucción de los procesos (Acevedo y Samacá, 2011), hay cierta predilección por el estudio de las protestas de 1971 (Hernández, 2007; Acevedo y González, 2011a; Villamil, 2010; Pardo y Urrego, 2003; Acevedo y Samacá, 2013). Por otro lado, existe un importante corpus de estudios sobre ciertas experiencias organizativas (Ruiz, 2002), políticas universitarias (Puyana y Serrano, 2000; Lucio y Serrano, 1992; Le Bot, 1979), y casos regionales como los de la Universidad Industrial de Santander (UIS) (Vargas, 1996; Acevedo y Gómez, 2000; Acevedo, 2004; Acevedo y González, 2011b), la Universidad del Valle (Ordóñez, 2007), la de Antioquia (Uribe, 1998), la Universidad Pedagógica Nacional (UPN) (Jiménez, 2001) o la Universidad Libre (VVAA, 2001) que tratan el período, aunque algunas veces de forma marginal.

Por consiguiente, este panorama podría complementarse. Es notable la ausencia de análisis sintéticos que permitan comprender el significado de la protesta estudiantil a escala nacional para ese período. Además, la historiografía del movimiento estudiantil presenta dificultades para acopiar herramientas analíticas de la sociología de los movimientos sociales y ofrecer explicaciones de las dinámicas de acción colectiva (Cote, 2014).

Este trabajo ofrece un análisis sintético de la protesta universitaria durante los años sesenta desde la perspectiva de la teoría del proceso político (McAdam, Tarrow y Tilly, 2005, p. 45; McAdam, McCarthy y Zald, 1999; Tarrow, 1997). Este enfoque sintetiza las distintas hipótesis planteadas para explicar por qué se produce la protesta social. Así, articula la preocupación por la dimensión estructural mediante el concepto de estructura de oportunidades políticas (EOP), pero también la dimensión de la agencia subjetiva con las categorías de estructuras de movilización y marcos de acción colectiva. La interacción entre estos tres factores permite comprender el desarrollo de la acción colectiva. Durante los años sesenta hay un auge de la protesta estudiantil en demanda de una reforma universitaria que hiciera posible la autonomía y el cogobierno. La protesta se explica principalmente por la 
influencia de las distintas expresiones de la izquierda, pues sus formas organizativas y sus marcos discursivos permitieron articular a los estudiantes entre sí y con otros sectores populares, para enfrentar un contexto político con pocas oportunidades políticas para la protesta configurado por el sistema político del Frente Nacional, que respondía predominantemente a los intereses de los partidos tradicionales y de sus clientelas políticas, se encontraba cerrado frente a las demandas de los sectores sociales emergentes producto de los procesos de modernización y respondió a la protesta social con aterradores niveles de represión que rayan con el terrorismo de Estado.

Para desarrollar este argumento, en primer lugar, se reconstruye la contienda política alrededor de la reforma universitaria, proceso que pasa por la politización inicial del estudiantado, su autonomización de los partidos tradicionales bajo la influencia de la izquierda y el incremento en los niveles de represión. En la segunda parte se examinan los factores que contribuyen a explicar el auge de la protesta universitaria en dichos años, analizando la estructura de oportunidades políticas, las estructuras de movilización y los marcos de acción colectiva que la sustentaron.

\section{La contienda política alrededor de la reforma universitaria}

Siguiendo a McAdam, Tarrow y Tilly (2005, p. 5) concebimos la contienda política como "la interacción episódica, pública y colectiva entre los reivindicadores y sus objetos cuando: (a) al menos un gobierno es uno de los reivindicadores y (b) las reivindicaciones, caso de ser satisfechas, afectarían a los intereses de al menos uno de los reivindicadores". La contienda política en que se enmarca la protesta universitaria en los sesenta se produce alrededor de la reforma universitaria. La politización del estudiantado inicia con su intenso activismo contra la dictadura de Rojas Pinilla (1953-1957), en lucha común con los partidos tradicionales. No obstante, una vez establecido el Frente Nacional tanto las políticas universitarias, centradas en la promoción de un modelo de universidad profesionalizante recomendado por la Alianza para al Progreso, como la paulatina articulación del estudiantado por la izquierda, los ubicará como uno de los principales críticos del sistema político, el cual responderá con represión.

\subsection{La ruptura con las élites bipartidistas y los nuevos repertorios de protesta}

A mediados de 1954, los estudiantes habían asimilado las demandas de la reforma de Córdoba. El 8 de junio de ese año, cuando se conmemoraba el día del estudiante caído, instituido desde el asesinato de Gonzalo Bravo Pérez en 1929, cayó asesinado otro estudiante, Uriel Gutiérrez (Medina, 1984: 85-122). Las protestas estudiantiles fueron reprimidas por el Batallón Colombia, que había regresado de la Guerra de Corea embebido con la doctrina contrainsurgente del "enemigo interno", dejando una cifra de entre diez y trece muertos (Jiménez, 2001: 60-61). Este hecho marcó la radicalización de los estudiantes contra la dictadura, agrupados en la Federación de Estudiantes Colombianos (FEC), que entonces se declaraba gremial y "apolítica” (Ruiz, 2002: 58). 
Ello explica la participación estudiantil en las movilizaciones que acabaron con el régimen autoritario, el 10 de mayo de 1957, lo que les granjeó la admiración de las élites bipartidistas (Archila, 2012: 77). Sin embargo, pronto empezaría un proceso de politización del estudiantado que se manifestó en el Primer Congreso Nacional Estudiantil, el 27 de junio de ese año, en el cual se creó la Unión Nacional de Estudiantes Colombianos (UNEC), organización que si bien reivindicaba la democracia y una reforma universitaria que hiciera realidad la autonomía, se declaraba independiente de los partidos políticos tradicionales (Ruiz, 2002: 68-69). La situación evolucionaría hacia un desencuentro entre estudiantes y élites políticas bipartidistas.

En el Segundo Congreso de la UNEC, del 20 al 24 de julio de 1958, la unidad estudiantil empezó a resquebrajarse con la discusión, impulsada por la Juventud Comunista (Juco), luego de que el Partido Comunista fuese legalmente reconocido con el retorno a la democracia, sobre el papel de los estudiantes en la sociedad (Ruiz, 2002: 76). También fue objeto de discusión la política universitaria de la Junta Militar, que había concedido participación en las máximas instancias de gobierno universitario a los gremios y a la Iglesia (Le Bot, 1979: 87). A ello se adicionaba la creación de la Asociación Colombiana de Universidades (ASCUN), entidad de carácter privado que representaría a las universidades hasta la fundación del Instituto Colombiano para el Fomento de la Educación Superior (ICFES) en 1968 (Lucio y Serrano, 1992: 61).

La política universitaria del Frente Nacional siguió los postulados de la Alianza para el Progreso, que imponía un modelo universitario profesionalizante y de estilo norteamericano. En la Universidad Nacional, la reforma del rector Mario Laserna (19581960) pugnaba por el profesionalismo, que a los estudiantes les sonaba como equivalente a socavar fines académicos y científicos de la universidad para convertirla en un politécnico (Ruiz, 2002: 99). El antiimperialismo estudiantil, que entonces empezaba a tomar fuerza, tenía fundamento en el rechazo a la influencia de la Alianza para el Progreso y, concretamente, a la pretensión de que la financiación de la investigación en las universidades públicas estuviese basada en las inversiones de fundaciones norteamericanas como la Kellog, la Rockefeller o la Ford.

El empeño de los gobiernos del Frente Nacional por desarrollar su política universitaria generaría más desencuentros. En 1961 se publica el informe de Rudolph Atcon, financiado por la Agencia Internacional para el Desarrollo (AID), el BID y la OEA, que tenía una intención explícita de despolitizar el estudiantado (Villamil, 2010: 133). El Informe defendía una perspectiva "ideológica y empresarial" de la universidad; como alternativa para reducir las huelgas recomendaba el incremento en las matrículas (Molina, 1978: 3840); se enmarcaba en las iniciativas de la Alianza para el Progreso por contrarrestar la influencia de la revolución cubana en el ámbito universitario y su propuesta de reforma universitaria se orientaba por el mercado de trabajo. Su intención era convertir las universidades en fundaciones de carácter privado con una financiación parcial del Estado, cuyo énfasis estaría puesto en la formación técnica (Hernández, 2007: 33-34). En fin, el Informe Atcon pretendía administrar la universidad como una empresa privada, no como un 
servicio público, reducir la intervención estatal en la política universitaria, la participación política estudiantil y generar mecanismos de autofinanciación que en la práctica significaban su privatización (Puyana y Serrano, 2000: 61).

Por esas razones, siguiendo a Archila (2012: 80), a principios de los sesenta el estudiantado sufre una radicalización política, empezando por la UNEC en donde predominaba la tendencia comunista. La prensa bipartidista retiró el respaldo al estudiantado universitario cuando este ganó autonomía de los partidos, así que durante el Frente Nacional el movimiento estudiantil dejó de recibir el reconocimiento de los partidos y pasó a tener una creciente influencia de la izquierda. Una encuesta aplicada a 400 estudiantes de la Universidad Nacional en junio de 1965 daba cuenta de la profundidad del cambio en las actitudes y convicciones del estudiantado: los jóvenes habían tomado distancia de las preferencias políticas de sus padres por los partidos tradicionales, en su lugar se orientaban mayoritariamente hacia su participación en protestas y organizaciones de izquierda, entre sus autores preferidos se encontraban Marx y varios de sus epígonos, mientras que el personaje político más admirado era el sacerdote Camilo Torres Restrepo (Latorre, 1980: 39-68). Sus movilizaciones tendrían un tratamiento militar, como alteraciones del orden público, sobre todo después de 1960 cuando emerge el repertorio de acción basado en la huelga o paro estudiantil (Jiménez, 2001: 67), en contra de la designación de autoridades universitarias y demandando la salida del rector Mario Laserna en la Universidad Nacional (Le Bot, 1979: 88).

Aunque las protestas estudiantiles tienen un importante crecimiento en la década de los setenta (Archila, 2003: p. 133), en los sesenta sus acciones tuvieron un notable protagonismo, tal como lo ilustra el Cuadro 1, de tal forma que los conflictos universitarios se expandieron al espacio urbano y la sociedad ya no sólo conoció a los estudiantes por los carnavales universitarios sino también por sus propuestas y demandas (Ruiz, 2002: 108109). A mediados de los años sesenta, tanto el "tropel" como la represión y criminalización, constituían repertorios típicos en las luchas estudiantiles.

Cuadro 1. Principales protestas universitarias en la década de los sesenta

\begin{tabular}{|c|l|}
\hline Año & \multicolumn{1}{c|}{ Acciones } \\
\hline 1961 & $\begin{array}{l}\text {-A principios de mayo se declara una huelga en la Universidad de Medellín. } \\
\text {-El 16 de mayo de 1961 el Consejo Superior Estudiantil de la Universidad Nacional se declara en paro en } \\
\text { solidaridad con la Universidad de Medellín. } \\
\text {-El 31 de agosto de 1961 los estudiantes de la Universidad Nacional se suman a la huelga de trabajadores de } \\
\text { Avianca y se producen enfrentamientos con la policía en el campus de Bogotá. }\end{array}$ \\
\hline 1962 & $\begin{array}{l}\text {-A principios de junio se desarrollan protestas en la UPTC. } \\
\text {-El 5 de junio de 1962 hay una movilización de estudiantes de la Universidad Nacional en Bogotá que es } \\
\text { reprimida por la policía. El Consejo Académico autoriza al rector para expulsar a los estudiantes que } \\
\text { participaron en los "disturbios". 6 estudiantes son expulsados. En respuesta, la Asamblea de la Universidad } \\
\text { se declara en huelga y las actividades universitarias son suspendidas por 20 días por orden de las directivas. }\end{array}$ \\
\hline 1963 & $\begin{array}{l}\text {-En agosto de 1963 los estudiantes de la Universidad Nacional y de la Distrital de Bogotá se solidarizan con } \\
\text { las protestas de los trabajadores petroleros en Barrancabermeja y realizan protestas demandando la } \\
\text { democratización del gobierno universitario y una tarifa diferencial de transportes. }\end{array}$ \\
\hline 1964 & $\begin{array}{l}\text {-El 24 de junio de 1964 la FUN declaró una huelga nacional de 48 horas. } \\
\text {-Durante mayo-agosto de 1964 tuvo lugar un conflicto en la UIS en demanda de la salida del rector, Juan } \\
\text { Francisco Villareal y por una reforma académica. La emblemática marcha de los estudiantes hacia Bogotá }\end{array}$ \\
\hline
\end{tabular}




\begin{tabular}{|c|c|}
\hline & $\begin{array}{l}\text { empieza el } 7 \text { de julio. } \\
\text {-El } 6 \text { de noviembre de 1964, el entonces candidato presidencial Alberto Lleras acude al auditorio de la } \\
\text { Facultad de Derecho de la Universidad Nacional para dictar una conferencia, pero es rechazado y retenido } \\
\text { por el estudiantado. Ante el hecho, el presidente Guillermo León Valencia decide intervenir en el campus } \\
\text { con el Ejército. }\end{array}$ \\
\hline 1965 & $\begin{array}{l}\text { - En mayo de } 1965 \text { una huelga en la Universidad de Antioquia escala hasta el nivel nacional y lleva al } \\
\text { gobierno a decretar el estado de sitio. Ese mismo mes tienen lugar las protestas en rechazo a la invasión } \\
\text { norteamericana a República Dominicana. }\end{array}$ \\
\hline 1966 & $\begin{array}{l}\text { - El } 20 \text { de agosto de 1966, ante la huelga en las universidades de Medellín y de Antioquia, el gobierno } \\
\text { Lleras implementa la militarización. } \\
\text { - El } 26 \text { de octubre de } 1966 \text { John Rockefeller fue invitado por el presidente Lleras Restrepo a inaugurar un } \\
\text { edificio del Instituto Colombiano Agropecuario financiado por él y dedicado a la investigación veterinaria } \\
\text { en el campus de la Universidad Nacional. Durante la visita, ambos fueron retenidos por la protesta de los } \\
\text { estudiantes. Como respuesta, el presidente determinó la ocupación militar del campus, la disolución de la } \\
\text { FUN y del Consejo Superior Estudiantil, cuyas sedes fueron allanadas, así como el arresto y el } \\
\text { procesamiento mediante consejos verbales de guerra de más de cien estudiantes responsables. }\end{array}$ \\
\hline 1967 & $\begin{array}{l}\text {-En junio de } 1967 \text { se produce la ocupación militar del campus de la UN por manifestaciones estudiantiles } \\
\text { contra el alza en los costos del transporte. }\end{array}$ \\
\hline 1968 & $\begin{array}{l}\text { - En } 1968 \text { se agudiza la protesta estudiantil en contra del Plan Básico, por la expulsión de la Fundación Ford } \\
\text { del Departamento de Sociología de la Universidad Nacional y de los cuerpos de paz de la Universidad del } \\
\text { Valle, entre otros. } \\
\text {-En abril hay protestas en la Universidad Nacional y un paro en la UIS. } \\
\text {-En septiembre hubo protestas en la Universidad del Valle, donde se acusaba a los miembros de los cuerpos } \\
\text { e paz de ser espías de la CIA, en medio de un grave problema de financiación de la Universidad. } \\
\text { - El } 14 \text { de octubre hubo una manifestación violenta por parte de los estudiantes de la Universidad La Gran } \\
\text { Colombia en Bogotá } \\
\text {-También en la UIS se produjeron protestas y un paro luego de que la Asamblea Departamental recortara el } \\
\text { presupuesto de la Universidad. } \\
\text {-El } 21 \text { de noviembre empieza una huelga en la Universidad del Valle en protesta por la participación del } \\
\text { rector en la convención del Partido Conservador y la intervención de las agencias norteamericanas en la } \\
\text { Universidad. } \\
\text {-También por esos días había protestas en la Universidad Nacional en contra de un proyecto que impediría } \\
\text { la repetición de un año. } \\
\text {-A comienzos de diciembre los estudiantes de la facultad de medicina en la Universidad Nacional entraron } \\
\text { en huelga, agitación que se extendió a toda la Universidad hasta ocasionar su cierre. }\end{array}$ \\
\hline 1969 & $\begin{array}{l}\text {-El } 19 \text { de mayo hay una gran protesta que lleva a la ocupación militar de los campus de la Universidad } \\
\text { Nacional y de la Universidad de Antioquia, las cuales permanecen cerradas por un mes y medio. Algunos } \\
\text { huelguistas son procesados en consejos verbales de guerra. } \\
\text {-En agosto se produce la primera huelga en una universidad privada, la Universidad La Gran Colombia. } \\
\text {-El } 14 \text { de octubre hay una manifestación violenta en esta misma Universidad. } \\
\text {-Al finalizar el año había considerable agitación en las universidades de Antioquia y de Medellín. Como } \\
\text { consecuencia, la primera fue objeto de cierre entre noviembre y febrero. } \\
\text {-Por la misma época se produjeron protestas en la UIS en contra del recorte del presupuesto por parte de la } \\
\text { Asamblea Departamental. } \\
\text {-El } 21 \text { de noviembre inicia la huelga en la Universidad del Valle demandando el retiro del rector por su } \\
\text { participación en política, particularmente en la convención del Partido Conservador, y en contra de la } \\
\text { injerencia de agencias norteamericanas en la Universidad. } \\
\text {-A fines de noviembre había protestas en la Universidad Nacional en oposición a un proyecto que de } \\
\text { aprobarse impediría a los estudiantes repetir un año. } \\
\text {-A comienzos de diciembre los estudiantes de la Facultad de Medicina de la Universidad Nacional se } \\
\text { declaran en huelga, que en pocos días se extiende al resto de la universidad ocasionando su cierre temporal. }\end{array}$ \\
\hline
\end{tabular}

Fuente: elaboración del autor con base en fuentes secundarias.

En varias ocasiones las protestas estudiantiles tuvieron como motivación la solidaridad con trabajadores, como los de Avianca en agosto de 1961 y los petroleros de Barrancabermeja 
en agosto de 1963 (Le Bot, 1979: 91). Ello permite inferir que existían articulaciones con sectores obreros determinados (VVAA, 1971: 34). Los sectores adversos a las demandas del movimiento estudiantil tomaron los enfrentamientos como un argumento a favor de la represión del estudiantado (Ruiz, 2002: 119-120). En adelante, habrá ingentes esfuerzos por parte de las élites políticas locales y nacionales por desarticular el activismo estudiantil, lo que tomará mayor ahínco luego de la formación del Ejército de Liberación Nacional (ELN), en 1964, debido a la influencia de esta guerrilla en un sector del movimiento (Vargas, 1996: $38)$.

\subsection{El protagonismo de la izquierda: la experiencia de la FUN}

Durante el primer semestre de 1963 se discutió el Estatuto Orgánico de la Universidad Nacional, el cual fue sancionado en octubre como ley 65. La norma creaba el Consejo Superior Universitario (CSU), como instancia representativa de los estamentos universitarios, eliminaba la representación de sectores gremiales en ese órgano de gobierno, pero no así de la Iglesia, y establecía la representación de estudiantes con dos miembros (Le Bot, 1979: 92). La aprobación de dicha ley fue duramente criticada por el estudiantado, puesto que no establecía con claridad el cogobierno y, salvo en la Universidad Nacional, la Iglesia y los gremios continuaban teniendo un gran influjo en los órganos directivos (VVAA, 1971: 33; Puyana y Serrano, 2000: 68).

Las discusiones alrededor del estatuto orgánico dieron pie al desarrollo en la Universidad Nacional de la reforma liderada por el rector José Félix Patiño (1964-1966), titulada "Universidad para el desarrollo". La reforma enfatizó la reorganización de las estructuras académicas, facultades y departamentos, dando lugar a la aparición de nuevas áreas de conocimiento y estableciendo el ciclo básico, conjunto de materias comunes a una facultad, entre otras cosas (Archila, 2012: 80). Si bien la reforma adoptaba en su retórica la visión modernizadora del Informe Atcon, el rector logró tener relaciones fluidas y cercanas con el estudiantado, hasta el punto de que sus representantes en el Consejo Superior Estudiantil (CSE) habían participado activamente en la implementación. Por eso, su gestión había despertado la oposición de las élites políticas, que desde entonces se opusieron a cualquier intento de cambio (VVAA, 1971: 23). El creciente inconformismo se expresó en la realización del Tercer Congreso Nacional Estudiantil, en Bogotá, en noviembre de 1963. Allí se creó la Federación Universitaria Nacional (FUN), organización que se presentaba como de carácter "esencialmente corporativo" y donde confluían distintas organizaciones de izquierda en función de la reivindicación de la autonomía universitaria.

En forma paralela, entre mayo y septiembre de 1964, se desarrolló el conflicto en la UIS (Le Bot, 1979: 92). Según Lucio y Serrano (1992: 68), "puede considerarse esa huelga como la mejor organizada en la historia del movimiento estudiantil, y 1964 como año del apogeo del mismo". Las protestas tenían como principales demandas la salida del entonces rector, Juan Francisco Villareal y una reforma académica flexible en relación con el promedio ponderado, así como una reapertura de la Universidad (Acevedo y González, 2011b: 266). El 7 de julio, de Bucaramanga partió una marcha hacia Bogotá con 25 
estudiantes, quienes, si bien no consiguieron sus objetivos inicialmente planteados, lograron una enorme visibilidad a nivel nacional. La marcha además significó una mayor articulación entre la Asociación Universitaria de Santander (AUDESA) y las organizaciones estudiantiles nacionales, bajo las consignas de "lucha antiimperialista y desestabilización del régimen político del Frente Nacional” (Vargas, 1996: 49).

\subsection{El aumento de la conflictividad y la represión}

A las discusiones entre las organizaciones del movimiento estudiantil, como uno de sus principales problemas, habría que adicionar el tratamiento represivo por parte del gobierno. En efecto, a medida que la FUN ascendió como organización nacional, también creció el tratamiento represivo en contra de la protesta estudiantil (Vargas, 1996: 46). El 6 de noviembre de 1964 Carlos Lleras Restrepo es invitado por la rectoría de la Universidad Nacional a dar una conferencia en el Aula Máxima de la Facultad de Derecho. Un grupo de estudiantes lo abuchean y el político liberal busca refugio. El presidente, Guillermo León Valencia, decide intervenir con el Batallón Guardia Presidencial para "rescatar" a Lleras (VVAA, 1971: 35). En estos años empiezan a ser comunes los enfrentamientos entre policía y estudiantes; según Le Bot (1979: 94), comienza a predominar el repertorio de protesta de confrontación callejera. Ese repertorio se complicaría debido a la creciente influencia de la insurgencia sobre el movimiento estudiantil, al encuadramiento del conflicto armado en los marcos interpretativos de la Guerra Fría y la consiguiente influencia de la Doctrina de Seguridad Nacional sobre las Fuerzas Armadas. El 7 enero de 1965 aparece el ELN con la toma de Simacota. A fines de mayo se crea el Frente Unido del Pueblo, más tarde su líder, el sacerdote y sociólogo Camilo Torres, decide irse al ELN y la guerrilla gana influencia entre el estudiantado (Le Bot, 1979: 101). Empero, luego de la muerte de Camilo, el 15 de febrero de 1966, se agudizaron las diferencias en el interior de la FUN: unos sectores pensaban que la lucha legal no valía la pena y había que tomar las armas. La Juco, por su parte, pensaba que el trabajo en la academia seguía siendo fundamental (Ruiz, 2002: 199).

El de Carlos Lleras Restrepo (1966-1970) sería el gobierno más reformista del Frente Nacional, pero tuvo una orientación tecnocrática frente a la educación superior y trató la protesta universitaria como un problema de orden público. La orientación tecnocrática tendió a concentrar los poderes en el ejecutivo y se expresó en la reforma constitucional de 1968. De ahí en adelante, los ministros, los jefes de departamentos administrativos y los gerentes de establecimientos públicos nacionales serían de libre nombramiento y remoción del presidente. Las universidades estatales nacionales eran concebidas como "establecimientos públicos", lo que amenazaba su autonomía. Además, el nombramiento de los rectores de universidades departamentales quedó bajo potestad de los gobernadores (Lucio y Serrano, 1992: 73). Entre otras cosas, el carácter tecnocrático del gobierno Lleras hacia la educación superior se manifestó en la reforma del ICETEX (1968), la creación de Colciencias, Colcultura y el ICFES, enmarcados en el proceso de modernización del Estado (Uribe, 1998: 546). 
El talante represivo contra la protesta contaba con un cierto consenso entre las élites políticas, puesto que los estudiantes habían pasado de ser "héroes de la democracia" en los inicios del Frente Nacional a ser considerados como "protoguerrilleros" (Uribe, 1998: 546). Por ejemplo, de acuerdo con Uribe (1998: 522), en marzo de 1965 un editorial de $E l$ Colombiano enmarcaba las protestas en la Universidad de Antioquia como parte de un supuesto plan insurreccional diseñado desde Moscú para toda América Latina y nombrado "Niño Rebelde". Para ese diario, la FUN tenía la tarea de ejecutar en Colombia ese plan subversivo.

La movilización en contra del modelo universitario provisto por el Informe Atcon motivó su moderación mediante el diseño de lo que se denominó el Plan Básico, en 1967 (Molina, 1978: 40). Esta propuesta fue elaborada por especialistas de la Universidad de California auspiciados por la AID y ASCUN, en distintos encuentros en El Paso (Texas) desde 1962, cuando Colombia se presentaba como el "país piloto" de la Alianza para el Progreso (Le Bot, 1979: 90-91). Según Lucio y Serrano (1992: 66), el Plan Básico era el primer estudio comprensivo de la universidad en Colombia e insertaba preocupaciones como los mecanismos de regionalización universitaria y la planeación educativa. Sin embargo, el Plan subordinaba la educación superior a las necesidades del sector productivo y el mercado de trabajo, reiteraba medidas tendientes a la privatización como el incremento en los valores de las matrículas, el fomento de subsidios a la demanda y de los créditos, y de la inversión de fundaciones (Kellog, Ford y Rockefeller) como vía para financiar la investigación.

La implementación del Plan Básico tuvo como uno de sus principales objetivos la despolitización del estudiantado, aumentando las cargas académicas, y la facilitación de la inversión de agencias extranjeras en las universidades públicas (VVAA, 1971: 26-27). Eso explica por qué durante los sesenta uno de los detonantes de la protesta sería la presencia de las fundaciones norteamericanas que interferían con el desarrollo misional de las universidades públicas (Ordoñez, 2007: 69). Así, la lucha por la derogatoria del Plan se planteó en términos de lucha contra el imperialismo (Uribe, 1998: 576).

El 26 de octubre de 1966 John Rockefeller fue invitado por el presidente Lleras Restrepo a inaugurar un edificio del Instituto Colombiano Agropecuario financiado por él y dedicado a la investigación veterinaria en el campus de la Universidad Nacional. Durante la visita, ambos fueron retenidos por una protesta estudiantil. Como respuesta, el presidente determinó la ocupación militar del campus y allanó las sedes de la FUN y del Consejo Superior Estudiantil. A la primera le retiró la personería jurídica y al CSE lo prohibió por decreto; además, retiró los dos representantes estudiantiles del Consejo Superior Universitario. Los estudiantes en protesta, más de un centenar, fueron arrestados y procesados en consejos verbales de guerra (Le Bot, 1979: 96; Ruiz, 2002: 209). En fin, hubo una represión que ni siquiera era policiva sino directamente militar y la supresión de las actividades políticas en la Universidad (VVAA, 1971: 38; Ordoñez, 2007: 97; Rodríguez, 1978: 74). 
En 1968 se agudiza la protesta estudiantil en contra del Plan Básico, en demanda de la expulsión de la Fundación Ford del Departamento de Sociología de la Universidad Nacional y de los cuerpos de paz de la Universidad del Valle, entre otros. En abril hay protestas en la Universidad Nacional y un paro en la UIS (VVAA, 1971: 40). En septiembre hubo protestas en la Universidad del Valle, donde se acusaba a los miembros de los cuerpos de paz de ser espías de la CIA, en medio de un grave problema de financiación de la Universidad (Ordoñez, 2007: 100). El gobierno responde con el Decreto 3157, que reforma las instituciones de educación superior, con lo que la autonomía universitaria es prácticamente anulada en la medida en que el gobierno universitario pasa a depender directamente del ejecutivo. Así, se establecen los denominados "rectores policía", como Jaime Sanín Echeverry en la UPN, y se recrudecen las tomas militares y cierres de algunas universidades (Jiménez, 2001: 79). A fines de 1968 se habían esbozado los puntos básicos de lo que sería el grueso de las demandas del movimiento estudiantil en 1971 (Uribe, 1998: 573). De hecho, quizás el punto más importante, la lucha por la reforma de los CSU para alcanzar el cogobierno, no era nuevo. Al igual que la denuncia de las agencias norteamericanas y el reclamo por la autonomía, había estado presente durante toda la década.

En los dos últimos años del gobierno Lleras, continuó la acción muchas veces violenta con cada vez mayores problemas de coordinación nacional para el movimiento estudiantil tras la desaparición de la FUN (Le Bot, 1979: 97). Ese año también se produjo la creación de los Comandos Camilistas y la emergencia de grupos anarquistas como Testimonio, en la Universidad Nacional (Le Bot, 1979: 102). El 14 de octubre hubo una manifestación violenta por parte de los estudiantes de la Universidad La Gran Colombia en Bogotá. Para entonces ya existía un importante nivel de agitación en las universidades de Antioquia y de Medellín, a tal punto que la primera será cerrada entre fines de noviembre y principios de febrero (Pécaut, 1989: 100). También en la UIS se produjeron protestas y un paro luego de que la Asamblea Departamental recortara el presupuesto de la Universidad (Vargas, 1996: 51). El 21 de noviembre empieza una huelga en la Universidad del Valle en protesta por la participación del rector en la convención del Partido Conservador y la intervención de las agencias norteamericanas (Pécaut, 1989: 100). También por esos días había protestas en la Universidad Nacional en contra de un proyecto que impediría la repetición de un año. A comienzos de diciembre los estudiantes de la facultad de medicina entraron en huelga, la cual se extendió a toda la universidad hasta ocasionar su cierre.

Así, al iniciar la década de los setenta, el panorama sociopolítico presentaba una inusual agitación pese a las numerosas discusiones internas en el movimiento estudiantil, que correspondía con el endurecimiento de la represión y la estigmatización de los activistas sociales como parte del "enemigo interno".

\section{Explicando las dinámicas de acción colectiva}

¿Cuáles son los factores que explican la protesta universitaria en los años sesenta? El enfoque de los procesos políticos plantea tres factores que permiten comprender las 
dinámicas de la acción colectiva: la estructura de oportunidad política, las estructuras organizativas y los marcos de acción colectiva. En los años sesenta confluyen un contexto que simultáneamente promueve la expresión de demandas sociales en términos de clase, debido a que los sectores sociales emergentes resultado de los procesos de modernización no encuentran canales políticos de expresión en el sistema político del Frente Nacional, y el ascenso de la represión oficial bajo la perspectiva de la Doctrina de Seguridad Nacional. Sin embargo, a pesar de los altos costos para la acción colectiva que este contexto supone, los estudiantes encontraron aliados en las distintas organizaciones políticas de izquierda, que los proveyeron de las formas organizativas y los marcos o discursos necesarios para formular sus demandas y articular otros actores descontentos.

\subsection{La estructura de oportunidades políticas}

La EOP designa los factores del contexto político que facilitan o dificultan la acción colectiva. Comprende la estructura política institucional y las relaciones informales de poder en un sistema político, y se usa como una variable o una serie de variables independientes para explicar el origen, la forma o incluso el impacto de la acción colectiva (McAdam, McCarthy y Zald, 1999, p. 23). McAdam (1999, p. 54-55), sostiene que dichos factores corresponden a: " 1 . El grado de apertura relativa del sistema político institucionalizado. 2. La estabilidad o inestabilidad de las alineaciones entre élites, alineaciones que ejercen una gran influencia en el ámbito de lo político. 3. La presencia o ausencia de aliados entre las élites. 4. Capacidad del Estado y su propensión a la represión". No obstante, no sólo las oportunidades políticas tienen efectos sobre las protestas. Existen factores sociales y culturales que tienen incidencia en el origen, desarrollo e impactos de los movimientos sociales. Por eso Ruch (1999: 266-269) propone el concepto de "estructura de contexto" que abarcaría: el contexto cultural, las actitudes y conductas que pueden apoyar el movimiento; el contexto social, el entorno que limita o facilita la construcción de identidades colectivas y la organización de los movimientos; y el contexto político, correspondiente a la EOP.

Las oportunidades provistas para la protesta estudiantil en los sesenta están configuradas por un contexto de modernización que motiva la emergencia de sectores medios urbanos, los cuales escapan a las redes clientelistas de los partidos tradicionales. Por tanto, sus demandas se expresan en términos de conflictos de clase $\mathrm{y}$, ante la ausencia de vías institucionales para expresarse y el aumento de la represión, encuentran aliados en la nueva izquierda, cuyo discurso se enmarca en el clima de transformación de la cultura a nivel internacional, y en las disidencias de los partidos tradicionales.

Existe un proceso societal de modernización que, como anteriormente se indicó, caracteriza el contexto de agitación en los años sesenta. En efecto, como sostiene Leal (1984: 58), en esos años se produce un cambio considerable en las actitudes políticas del estudiantado universitario: una composición social predominante de clase alta y media alta ligada a los partidos tradicionales paulatinamente se transforma en una composición predominante de esa clase media en pugna por el ejercicio del poder político, pero que debido a las 
restricciones de la democracia bajo el Frente Nacional no encuentra apertura en el sistema político para canalizar sus demandas. Se trata de un proceso enmarcado en profundos cambios estructurales de la sociedad colombiana producto del proceso de desarrollo centrado en el Estado y las consiguientes dinámicas de urbanización, ampliación de los índices de escolaridad y secularización, entre otros (Archila, 2012: 78-79).

Ese inconformismo coincide con un contexto internacional favorable a la protesta marcado por el protagonismo de los movimientos sociales, la revolución cultural en China, las guerras de liberación nacional y el proceso de descolonización, los movimientos juveniles y estudiantiles alrededor de la simbólica jornada de mayo de 1968 en Francia. Todo lo cual conduciría a la emergencia de lo que entonces se denominó la "nueva izquierda", que tuvo en América Latina un gran influjo proveniente de la revolución cubana (1959) con su doctrina del foquismo y, a partir de 1960, de la ruptura chino-soviética (Archila y Cote, 2009: 68). Además, es la época de una transformación cultural global en el que cabe resaltar la emergencia de una cultura juvenil altamente politizada, expresada por ejemplo en la "revolución sexual” y el utopismo (Beltrán, 2002: 162).

El contexto político nacional se caracteriza fundamentalmente por las consecuencias del Frente Nacional (1958-1974), que amainó la disputa entre los partidos tradicionales pero, debido a las restricciones de la competencia política producto del reparto del poder estatal entre ambas colectividades, contribuyó a la generación de nuevos conflictos que se expresaron en términos de lucha de clases (Archila, 1997: 190). Las diferencias ideológicas entre los partidos se desdibujaron paulatinamente al tiempo que su monopolio sobre el Estado excluía proyectos alternativos de desarrollo (Lucio y Serrano, 1992: 49-50). Los sectores sociales emergentes, medios y populares, fueron excluidos de la toma de decisiones durante el Frente Nacional. En consecuencia, sus demandas tenían pocos canales institucionales para tramitarse, lo que coadyuvaría a la agudización de los conflictos sociales comprendidos como conflictos de clases.

En el contexto de la guerra fría, esta situación de exclusión se tradujo en un tratamiento represivo a cualquier manifestación que se saliera de los moldes del bipartidismo. Como sostiene Uribe (1998: 515), “el imaginario comunista y las tesis del "enemigo interno", en boga en ese momento en toda América Latina, contribuyeron a ver en cada protesta social la mano de Moscú o de Pekín". De acuerdo con Múnera (1998: 145-154), el marcado recurso a la represión se explica por una transformación en los mecanismos de reproducción de la hegemonía bipartidista. Antes del Frente Nacional la hegemonía se sustentaba sobre todo por la vía de la adscripción ideológica a los partidos, prevalecía el consenso sobre la coerción directa en la relación entre clases dominantes y populares. En el Frente Nacional hay una evolución que va del clientelismo señorial a un clientelismo transaccional en la relación partidos-clases populares. Por tanto, cada vez hay menos adscripción ideológica a los partidos, que al fundirse en el Frente Nacional pierden sus diferencias, y cada vez más emerge un clientelismo instrumental. En consecuencia, los canales de construcción del consenso alrededor de los partidos se restringe a quienes forman sus redes clientelistas y acceden al reparto de la "torta burocrática". Esto se 
manifestó en un deterioro de la legitimidad y un aumento de los conflictos sociales. Por todo eso, tomó preponderancia la coerción militar y policial para sustentar la hegemonía, básicamente por dos vías. Por una parte, mediante la autonomía de las Fuerzas Militares en el manejo del orden público, consagrada mediante el discurso del presidente Alberto Lleras a los militares el 9 de mayo de 1958 y reforzada por la Doctrina de Seguridad Nacional y el combate al "enemigo interno". Por otra parte, la represión también se vio fortalecida por el continuo uso del estado de sitio, sobre todo porque la justicia penal militar juzgaba delitos de alteración del orden público cometidos por civiles.

Sin embargo, los altos costos de la protesta social en términos de represión fueron compensados por la influencia ideológica y organizativa de la izquierda. En efecto, los sectores universitarios encontrarían aliados en las organizaciones de la naciente nueva izquierda. Siguiendo el análisis de Múnera (1998: 159-192), el deterioro de la adscripción partidista que implicó el Frente Nacional favoreció el surgimiento de organizaciones políticas y sociales fuera del control bipartidista, la mayoría de izquierda. A ello se sumó una diversificación ideológica y organizativa de la izquierda a causa de las influencias internacionales como la revolución cubana y la evolución internacional del socialismo, de tal manera que el monopolio que el Partido Comunista había tenido sobre la izquierda se resquebrajó por la aparición de organizaciones foquistas, socialistas-trotskystas y maoístas, ante las cuales las estrategias reformistas del Partido aparecían como la antítesis de un proyecto revolucionario como el cubano. A la diversificación de la izquierda se adicionaban las disidencias de los partidos tradicionales, el Movimiento Revolucionario Liberal, entre 1960 y 1968, y la Alianza Nacional Popular, a partir de 1964, así como el Frente Unido del Pueblo en 1965, que cuestionaron la legitimidad del sistema político en su conjunto.

Pero los aliados de la protesta universitaria no sólo se encontraron en el ámbito político, puesto que como anteriormente se indicó, muchas veces las protestas estudiantiles sintonizaron con protestas de distintos sectores obreros y populares. Más aún, otros estamentos universitarios, particularmente los profesores, también rechazaron políticas como el Plan Básico (Lucio y Serrano, 1992: 75). Es el caso, por ejemplo, de la Asociación Sindical de Profesores Universitarios, fundada en la Universidad Nacional de Bogotá en mayo de 1966 (Villamil, 2010: 238). En algunas coyunturas los rectores de universidades privadas también objetaron la implementación del Plan Básico, como en julio de 1967, cuando protestaron por considerar que ASCUN y el Consejo de Rectores habían sido desplazados por el gobierno central y entidades extranjeras en la formulación de la política de educación superior, lo cual vulneraba la autonomía universitaria (Aguilera, 2011: 230). También objetaron parte del plan por imponer demasiado control a cargo del Consejo Nacional de Educación Superior (Ordoñez, 2007: 91). En fin, durante toda la década fue común la participación de estudiantes de universidades privadas donde la izquierda realizaba trabajo organizativo (Ruiz, 2002: 73) e incluso de estudiantes secundaristas (Acevedo y González, 2011a: 229 nota 28). 


\subsection{Las estructuras de movilización}

Las "estructuras de movilización" son "los canales colectivos tanto formales como informales, a través de los cuales la gente puede movilizarse e implicarse en la acción colectiva" (McAdam, Mc-Carthy y Zald, 1999, p. 25). Se trata de redes de relaciones sociales y formas de asociación con distintos grados de formalización cuyo objetivo no es la movilización pero que pueden soportarla, como las familias, las redes de amigos, las asociaciones con distintos fines, las organizaciones no gubernamentales, los gremios o los partidos, y organizaciones cuyo fin es promover la movilización: organizaciones del movimiento social (McCarthy, 1999, p. 206). La protesta universitaria en los años sesenta estuvo soportada en las redes de sociabilidad de la vida universitaria, en los esfuerzos organizativos de tipo gremial a nivel nacional $\mathrm{y}$, fundamentalmente, al activismo de organizaciones de izquierda.

Los procesos organizativos estudiantiles de los años sesenta sólo se pueden comprender si se parte de los antecedentes en la disputa contra la dictadura rojista, pues como se indicó anteriormente es el momento en que el movimiento estudiantil inicia su proceso de politización, inicialmente de la mano de los partidos tradicionales. Durante la dictadura se constituyeron dos organizaciones estudiantiles. La Federación Universitaria de Colombia (FUC), se fundó como resultado del Congreso Nacional Universitario, realizado entre el 8 y el 12 de abril de 1953, bajo influencia del ala laureanista del Partido Conservador y, luego, del ministro de gobierno de Rojas Pinilla, Lucio Pabón Núñez (Jiménez, 2001: 59). Debido a la represión del gobierno de Rojas Pinilla contra los estudiantes, el 8 y 9 de junio de 1954, se crea la Federación de Estudiantes Colombianos (FEC), con una dirigencia predominantemente liberal proveniente de universidades privadas como la Libre y el Externado, dado que las públicas estaban bajo control del autoritarismo, aunque ya con alguna influencia de la izquierda (Archila, 2012: 77). La FEC se presentaba como una organización gremial, no política, retomaba el programa de Córdoba y luchaba por el restablecimiento de la democracia. Su estructura organizativa estaba basada en los consejos estudiantiles de algunas universidades, varios de los cuales eran órganos institucionalizados en el gobierno universitario (Ruiz, 2002: 63).

Tras las movilizaciones que terminaron con la dictadura, el 10 de mayo de 1957, inicia otro proceso organizativo en el cual empieza a tener una creciente influencia la izquierda. El 27 de junio de ese año se celebra el Primer Congreso Nacional Estudiantil, que cuenta con la participación de distintas universidades y el apoyo de la FEC y de la FUC. En dicho evento se decide crear la Unión Nacional de Estudiantes Colombianos (UNEC), que se declaró como gremial e independiente del Estado y de los partidos políticos, con un programa dirigido a la reforma universitaria, enfatizando en la necesidad de garantizar la autonomía y la democratización del país (Ruiz, 2002: 68-69). En realidad, esta organización significó un viraje desde la influencia de los partidos tradicionales sobre el estudiantado hacia la izquierda, principalmente por la rivalidad que se suscitaba con la Confederación de Estudiantes Universitarios de Colombia (CEUC), de tendencia conservadora, y que llevó a la Juco y a las Juventudes del MRL, que entonces estaban muy organizadas en la 
Universidad Libre, a propiciar la formación de la UNEC (Le Bot, 1979: 87; VVAA, 1971: 29).

Entre el 20 y el 24 de julio de 1958 se realiza el Segundo Congreso de la UNEC en Cali. Este encuentro estuvo marcado por la discusión en torno al papel que los estudiantes deberían asumir en la sociedad colombiana, promovida por la Juco. También se discutió la influencia del clero en el gobierno universitario y la orientación que la Junta Militar estaba dando a la política universitaria, principalmente la participación que le había concedido a grupos de interés gremiales y a la Iglesia en los Consejos Superiores Universitarios, en un estatuto orgánico (decreto legislativo 136 del 30 de abril de 1958) que estaría vigente hasta 1971 (Le Bot, 1979: 87). En parte por estas razones, estudiantes cercanos a los partidos tradicionales denunciaron el Congreso como un evento manipulado por el comunismo internacional. No obstante, ello no impidió que se aprobaran nuevos estatutos para la organización ni que en las declaraciones finales se resaltara el rol del estudiantado en la superación de los problemas sociales del país, en una perspectiva democrática y revolucionaria (Ruiz, 2002: 79-80)

De acuerdo con Ruiz (2002: 84-85), la UNEC empezó su declive luego del Tercer Congreso realizado en Barranquilla. La organización intentó proyectarse como una confederación nacional de estudiantes sin contar con las bases sociales necesarias, puesto que su estructura dejaba por fuera los canales institucionales de representación de los estudiantes en las universidades, lo que se traducía en que quienes en ella participaban lo hacían a nombre propio y no necesariamente representaran instituciones. Además, la influencia que el Partido Comunista tenía sobre la organización la hacía poco atractiva para la naciente nueva izquierda (Archila, 2012: 80). Esta variopinta corriente se apartaba del Partido Comunista porque no compartía su estrategia de frente popular, que interpretaba como reformismo, tomó distancia de la UNEC y en su lugar aprovechó el sistema de organización oficial, especialmente en la Universidad Nacional, que vinculaba los estudiantes por carreras y facultades, y cuya representación era el Consejo Superior Estudiantil (CSE).

Precisamente los consejos estudiantiles, establecidos a partir de la reforma implementada por la Junta Militar en 1958, pasaron a convertirse en el núcleo organizativo del movimiento estudiantil, sobre todo en la Universidad Nacional (Ruiz, 2002: 85). El nuevo estatuto orgánico instauró como instancia máxima de representación el Consejo Superior Estudiantil, que contaba con legitimidad entre los estudiantes debido a que sus miembros eran elegidos de manera transparente y democrática: el proceso iniciaba en la elección por voto directo de la representación por cursos y desembocaba en la elección, también directa, del Consejo Estudiantil por Facultad, hasta llegar al Superior (Uribe, 1998: 575). Así lo testimonia un estudiante de la época:

La representación estudiantil se reconocía claramente en el Consejo Superior Estudiantil. Su legitimidad no se ponía en duda, pues, de hecho, todos participábamos en su elección, así: se elegían los consejos estudiantiles de cada facultad, por el sistema de votación directa en torno a planchas, y luego los presidentes de estos consejos se 
convertían en los representantes ante el Consejo Superior Estudiantil... Las asambleas se hacían en el teatro al aire libre y, aunque eran exhaustivas en el examen de los problemas que nos convocaban, no llegaron a tener esa duración maratónica de las de nuestros estudiantes actuales (Ruiz, 1998: 585)

También existía la Asamblea General Estudiantil, organismo que se reunía extraordinariamente por citación del CSE o una vez al año, compuesta por los Consejos Estudiantiles de cada Facultad. Según Ruiz (2002: 92) estas estructuras estuvieron en la base de la formación de un movimiento estudiantil de masas en la Universidad Nacional. Las formas organizativas institucionalizadas serían aprovechadas en el proceso organizativo más significativo de los años sesenta: la Federación Universitaria Nacional (FUN) entre 1963 y 1966. Esta organización fue creada para dar respuesta a la crisis de la UNEC en el Tercer Congreso Nacional Estudiantil, en noviembre de 1963. El tema se había discutido desde mayo, con la realización del Segundo Congreso de la Unidad Estudiantil en Medellín. Allí se debatió la creación de una federación de universidades públicas que luchara por el cogobierno universitario a nivel nacional, como fórmula para hacer posible la autonomía universitaria (VVAA, 1971: 30-31). La Juco también hizo suya la idea de crear una federación nacional de estudiantes. En 1963, organizaciones de la nueva izquierda comienzan a actuar en el Consejo Superior Estudiantil de la Universidad Nacional, que se convierte en un organismo orientador del movimiento a nivel nacional, desde donde finalmente se promueve la creación de la FUN (VVAA, 1971: 32-33). Al igual que la UNEC, la FUN se presentaba como independiente de los partidos políticos y la Iglesia; sin embargo, con el tiempo fue mayoritariamente influida por la nueva izquierda, sobre todo procubana y maoísta. Así mismo, la FUN recogía los planteamientos de la reforma de Córdoba, pero su plataforma programática no se reducía a ellos, pues postulaba la participación activa del estudiantado en la solución de los problemas de la sociedad colombiana (Ruiz, 2002: 150).

La base de la organización estaba conformada por los CSE de facultad. Había un órgano central que era el Congreso Nacional Universitario, al que asistían delegados con voz y voto, y observadores, solo con voz. Una instancia intermedia era el Consejo Directivo Nacional, integrado por los representantes de los organismos superiores de cada universidad con funciones administrativas y de fiscalización. También había un Comité Ejecutivo, que era el representante del Congreso Nacional Universitario por un año. Sólo podrían ser miembros de la FUN los organismos de representación estudiantil en las universidades, no grupos de estudiantes (Ruiz, 2002: 159-160). Este modelo permitió que la organización superara el hiato entre las bases y las dirigencias característico de las experiencias anteriores, FEC y UNEC, no sólo porque los consejos estudiantiles eran oficiales, sino también porque aseguraban su legitimidad tanto por los transparentes y democráticos procesos de elección como por algunas prerrogativas que tenían; por ejemplo, expedir credenciales para beneficios de bienestar como el acceso a almuerzos (Acosta, 1998: 589). Esto posibilitaría quizás la única experiencia de una organización estudiantil a nivel nacional en la historia del país. 
Desde luego, además de los organismos institucionales, las estructuras de movilización estudiantil se apoyaban en todo tipo de asociaciones de carácter cultural, deportivo y regional que pululaban en aquellos agitados años. Por ejemplo, según Aguilera (2011: 141142), en la Universidad Nacional se establecían densas redes de relaciones sociales en la cotidianeidad de las residencias estudiantiles, como las colonias, compuestas por afinidades de procedencia regional de los estudiantes (pastusa, paisa, boyacense, etc.), y los combos, definidos en virtud de la distribución espacial de las viviendas estudiantiles en los edificios. Así mismo, las organizaciones nacionales, FEC, UNEC y FUN, tenían unas ramificaciones regionales que, como se dijo, estaban organizadas en función de los consejos estudiantiles, pero también estaban constituidas por organizaciones estudiantiles como la AUDESA en Santander (Acevedo, 2004: 239-300) y la Federación de Estudiantes de la Universidad del Valle (FEUV), que había sido auspiciada por las directivas de esa universidad (Ordóñez, 2007: 94). De acuerdo con Vargas (1996: 28-31), AUDESA se constituyó formalmente el 25 de abril de 1953, inicialmente de forma gremial, pero transitó luego por las demandas antidictatoriales y favorables al Frente Nacional, para paulatinamente ir cobrando autonomía de la mano de la influencia de la revolución cubana y la nueva izquierda.

En octubre de 1964 se realizó en Bogotá el Segundo Congreso de la FUN. A él asistieron representantes de 29 universidades y cerca de 30.000 estudiantes. La agenda de discusión incluyó asuntos como el imperialismo, el conflicto armado, el militarismo, la dependencia, la educación pública y la democracia (Vargas, 1996: 53). Sin embargo, ya era palpable la fractura interna entre las tendencias "reformistas" encabezadas por la Juco y las propuestas más radicales de otros grupos (VVAA, 1971: 34). Según Archila (2012: 82), la FUN asumió la "línea insurreccional" en 1965, en parte influida por el ingreso de Camilo Torres y otros directivos a la guerrilla. En este contexto, dos factores llevaron al declive de esta experiencia organizativa. Por una parte, las confrontaciones internas entre las distintas organizaciones de izquierda (Le Bot, 1979: 99; Ruiz, 2002: 211). Por otra, la represión que sobre la organización sobrevino luego de los hechos, ya comentados, del 26 de octubre de 1966. Al clausurar los Consejos Estudiantiles e ilegalizar a la FUN, el gobierno de Carlos Lleras forzó a los dirigentes a la clandestinidad y desincentivó entre los estudiantes la formación de una organización gremial nacional, con lo cual las bases del movimiento estudiantil pasaron a depender de las organizaciones políticas de la izquierda (Puyana y Serrano, 2000: 72).

Con todo, la trayectoria de las organizaciones estudiantiles propiamente dichas es inseparable de las organizaciones políticas de izquierda. En la FUN hacían presencia diversas expresiones: la Unión Nacional de Estudiantes Universitarios (UNEC), la Juventud Comunista (JUCO), las Juventudes del Movimiento Revolucionario Liberal (JMRL), la Confederación de Estudiantes Universitarios de Colombia (CEUC) y el Movimiento Obrero Estudiantil Campesino (MOEC). De acuerdo con Vargas (1996: 53), la FUN se constituyó en una organización que representó los ideales de la "nueva izquierda" y su oposición al Frente Nacional. 
El alza en el costo del transporte público a principios de 1959 produjo una oleada de protestas obreras y estudiantiles de la cual surgió el Movimiento Obrero y Estudiantil ( 7 de enero), la primera organización de la nueva izquierda que más tarde se convierte en Movimiento Obrero y Estudiantil Campesino (MOEC) (Archila, 2012: 80). En Medellín surge Acción Revolucionaria Colombiana, como una disidencia del Partido Comunista en 1962 y más adelante emerge el Partido de la Revolución Socialista. En fin, la nueva izquierda sería presa de agudas discusiones que con frecuencia llevaron a divisiones internas. Tales discusiones se originaban fundamentalmente en diferencias sobre cuestiones teóricas y prácticas de la revolución. Así, aunque la nueva izquierda tenía en común el romper con los partidos tradicionales y con el Partido Comunista, se distanciaban tanto en la lectura de la realidad política como en la definición de la táctica y la estrategia apropiada (Múnera, 1998).

\subsection{Los marcos de acción colectiva}

Los marcos de acción colectiva son "significados compartidos que impulsan a las personas a la acción colectiva" (Tarrow, 1997: 57), "esquemas interpretativos" mediante los cuales los participantes en un movimiento social construyen una representación de la realidad (Snow y Benford, 1992: 137). Se trata de concepciones del mundo que se construyen estratégicamente con el objetivo de legitimar la causa y articular personas y grupos a la acción colectiva (McAdam, McCarthy y Zald, 1999, p. 27). El marco se construye en medio de un proceso conflictivo que involucra distintas visiones del mundo, entre los participantes en un movimiento social y sus adversarios (Zald, 1999, p. 370; Rivas, 1998, p. 207). Analizar un marco de acción colectiva implica identificar: (1) el diagnóstico de la realidad, porqué las cosas no son como deberían ser y quiénes son los responsables, el antagonismo; (2) la identidad, o la autodefinición de un "nosotros" a partir de articulaciones, que están de acuerdo con (3) una solución a los problemas, un deber ser en función del cual se produce la acción colectiva.

Las protestas universitarias de los sesenta construyeron un marco de acción colectiva en el cual el problema radicaba en la carencia de autonomía universitaria, producto del subdesarrollo que beneficiaba los agentes imperialistas y las élites nacionales, constituidos en sus adversarios. La identidad estaba íntimamente articulada con el discurso de la izquierda y se concebían como revolucionarios, lo que les permitía definir sus adversarios y aliados, en términos generacionales y de clase, en función de una universidad a la altura de los problemas que un país subdesarrollado le demandaba.

\section{a. El problema y sus responsables}

Las distintas organizaciones estudiantiles realizaron un diagnóstico de los problemas de la universidad y del país en el cual se resaltaba fundamentalmente la carencia de autonomía y las dificultades materiales que tienen las universidades, principalmente las públicas, para desarrollar su misión en la sociedad colombiana. En este diagnóstico, la situación de la universidad estaba determinada por la realidad del país, que entonces se concebía como 
subdesarrollado y dependiente, y los principales responsables de la situación estaban constituidos por quienes se beneficiaban en el país de esta situación y el imperialismo.

Así, en el diagnóstico del problema se hacía sentir con fuerza la influencia discursiva de las distintas organizaciones de izquierda. La problemática universitaria pasaba primero por el diagnóstico de la sociedad colombiana. Por consiguiente, del subdesarrollo se deducían los problemas de la educación. La resolución pasaba bien por vía de la revolución, bien por vía de la reforma, lo que llevó no pocas tensiones en el interior del movimiento estudiantil (Ruiz, 2002: 153). Los universitarios no eran ajenos a los principales problemas de la universidad, que podrían resumirse en la carencia de una autonomía real, las carencias en la financiación de las universidades públicas que trataban de resolverse con la intervención de agencias norteamericanas y el crecimiento de la universidad privada.

Una síntesis de este diagnóstico fue la ponencia de Fernando Correa, presentada y aprobada en el segundo y tercer Congreso Universitario Nacional, en 1963 por parte del CSE de la Universidad Nacional (Correa, 1963). El texto, que sustenta cada uno de sus argumentos con cifras y referencias a estudios de la Fundación Ford y al informe del Padre Lebret, arrancaba con un análisis de los problemas de la universidad colombiana para finalizar situándolos en el contexto del subdesarrollo. Existía, por ejemplo, una crítica a la repetición de las carreras y su concentración en ciertas ciudades, cuestión que interpretaba como una deficiente utilización de recursos que no respondía a las necesidades del país. También se criticaba la "falta de concordancia entre las facultades existentes y las necesidades de la región donde se encuentran", la "falta de concordancia entre las necesidades del país y la universidad en general", y una tendencia al crecimiento de la educación privada en relación con la pública que significaba una mayor exclusión social. La crítica de la Universidad privada se basaba en dos argumentos. Por una parte, seleccionaba a los estudiantes en función de la posición económica y no de los méritos, lo cual preocupaba porque la tendencia que revelaban sus cifras era hacia el predominio de la universidad privada sobre la pública:

...la universidad privada -salvo algunas excepciones- es una universidad antipopular, y es una universidad destinada a restringidos sectores de nuestra población que sí pueden comprar la educación a ese precio.

...como lo hemos probado atrás, la universidad privada -salvo excepciones menoreses una universidad cuyo personal es extraído de grupos económicamente favorecidos y minoritarios en relación al país. Ello se manifiesta y se prueba por el elevado costo de las matrículas que constituyen un obstáculo para que el acceso a ellas se haga en función del mérito respectivo. Es una universidad que está vedada a cerca del $80 \%$ de nuestra población.

Si consideramos además su elevada tasa de crecimiento, y su inminente dominio o supremacía en la educación superior, el problema es más grave aún.

De su elevada tasa de crecimiento podemos deducir que en el panorama de la educación superior la tendencia (estadística) predominante no es la de garantizar el libre acceso a la educación superior, sino la de garantizar el acceso a ella de grupos favorecidos económicamente, minoritarios con relación al país (Correa, 1963: 248249). 
Por otro lado, el enrolamiento en función de la posición económica en lugar del mérito implicaba un desperdicio de recursos de cara a la meta del desarrollo del país:

Queremos, además, resaltar una consecuencia especialmente nociva para el país, que trae la selección en base a la situación económica y no en los méritos del individuo: la no utilización o desperdicio de enormes recursos humanos.

En efecto, de acuerdo no sólo a la concepción democrática de la igualdad del hombre, sino a la concepción científica a la que han llegado la sociología, la sicología y la antropología de que el nivel de inteligencia promedio de los grupos de color, de ingresos, de origen geográfico es igual -salvo leves variaciones. Al descalificarse el acceso a un gran grupo de desfavorecidos económicamente a la educación superior se está perdiendo un enorme potencial intelectual. De acuerdo al estado actual de la educación superior en Colombia, podemos afirmar que, en muchos casos, individuos mediocres pero favorecidos económicamente están ocupando plazas que, potencialmente y dadas otras condiciones que luego trataremos, bien podrían ocupar individuos altamente dotados pero pertenecientes a clases bajas (Correa, 1963: 249).

De forma indirecta, ese mismo problema lo encontraba en la Universidad Nacional, donde "en términos de clase social nos encontramos con que un 5,4\% de los estudiantes se catalogaron como clase baja o media baja, un $83,3 \%$ como clase media, un $7,6 \%$ como clases media alta, y un 6,7\% como alta" (Correa, 1963: 249). Eso se explicaba por las limitaciones de presupuesto de la Universidad que no alcanzaba para ampliar los cupos, pero también por las deficiencias de acceso al sistema educativo en primaria y bachillerato. Por consiguiente, democratizar el acceso a la universidad pasaba primero por cambios sociales estructurales que en la época implicaban superar el subdesarrollo:

De lo anteriormente expuesto salta a la vista la relación entre la educación superior y el subdesarrollo del país. Por una parte el subdesarrollo, que se manifiesta en un nivel de vida extremadamente bajo para la gran masa de la población, ya es una barrera para que la universidad sea realmente democrática. Aún sea en el solo aspecto de reclutamiento de personal... (Correa, 1963: 251).

La lógica de la exposición terminaba identificando las causas del subdesarrollo, el imperialismo y, más en general, la dependencia económica, expresada, por ejemplo, en la "inversión de capitales extranjeros en condiciones leoninas para la economía del país" (Correa, 1963: 253). Este diagnóstico del problema estaría presente en otros documentos del movimiento estudiantil durante la década de los sesenta. Con el paso del tiempo, a estos problemas estructurales se agregarían los problemas propios de cada coyuntura. Así permiten inferirlo las consignas que vitoreaban los estudiantes en las manifestaciones, tal como lo recuerda uno de los actores de la época en Medellín:

...marchábamos desde la Universidad, tomando la Carrera Bolívar al ritmo de "Che, che, revolución", "Abajo el Plan Básico", "Allí están, ellos son, los que engañan la nación", "Yanqui go home", "Fuera Gringos de Vietnam", "Fuera los cuerpos de paz, espías a sueldo de la CIA", entre otras consignas, y terminábamos en la plazuela 
Nutibara, donde contribuíamos al caos del tránsito hasta que llegaba la policía y se incitaban la trifulca y la pedrea"..."fuera la bota militar de las universidades colombianas" y "fuera rectores policías" (Ruiz, 1998: 586- 587).

En fin, a partir de ese diagnóstico se identificaban los responsables de la situación y antagonistas del movimiento. De un lado, quienes se aprovechaban la situación para lucrarse, observados mediante el filtro ideológico de la izquierda. En este sentido, el documento de Correa (1963: 238) advertía en su inicio:

Claro está que las evidencias que aquí traemos no lo hacen todo. Quienes se lucran de la situación actual del país, las conocen tal vez mejor que nosotros. Otro obstáculo contra el que a veces nada se puede es el recelo y el prejuicio sistematizados, producto de la propaganda y "slogans" con que un sistema busca perdurarse. Y que usualmente tienen un marcado matiz anticomunista (Correa, 1963: 238).

De otro lado, el imperialismo y sus consecuencias. Así por ejemplo, el artículo 4 de los estatutos de la UNEC declaraba: "la UNEC condena la militarización de la juventud, la violencia en todos sus órdenes, y los imperialismos políticos, económicos y coloniales opuestos a la libre determinación de los pueblos" (UNEC: 1958: 224).

\section{b. La identidad}

La representación de los estudiantes en los años sesenta, como estudiantes revolucionarios, les permitió definir con claridad sus adversarios para articular a sus luchas otros sectores populares o para articularse a las causas de éstos, tal como se ha visto anteriormente. El compromiso podría ir desde la militancia en la organización estudiantil o política, hasta su vinculación con proyectos armados, ejemplo de lo cual puede ser la trayectoria de Antonino María Larrota González, reconstruida por Díaz (2010). La identidad política se enmarcaba en una transformación cultural más profunda, como afirma Archila (2003: 397):

Las imágenes sobre ellos también cambiaron al ritmo de esa transformación. Algo va del pausado universitario vestido de "doctor" en los años de la caída de la dictadura, al desaliñado barbudo de los setenta, de quien no se sabía si imitaba al Che o a los Beatles. Así mismo las formas de lucha se fueron modificando a la par con la radicalización de las demandas: de los masivos desfiles por las ciudades se pasó a los descontrolados tropeles en los alrededores de los predios universitarios.

Esta transformación cultural introduce en la conformación de la identidad estudiantil, dos tensiones. Por una parte, una cierta tensión entre el componente de clase y el factor generacional de la identidad política. El factor de clase generó no pocos problemas en un estudiantado proveniente de clases medias y cuya lectura del marxismo lo ubicó como un actor secundario en los procesos de transformación respecto del proletariado. La gran mayoría se declaraba marxista, dentro de alguna de las corrientes de la izquierda, pero no se concebía al estudiantado como el sujeto de cambio o incluso como vanguardia revolucionaria sino como un sector progresista de la pequeña burguesía (Acevedo y Samacá, 2013: 218). Empero, esta nueva generación atravesaba por la experiencia común 
del cambio cultural en curso, por lo que el componente generacional de la identidad conllevó procesos de articulación entre los miembros de la misma. En medio de sus tensiones, tanto el factor de clase como el generacional contribuyen a comprender las articulaciones entre sectores estudiantiles de universidades privadas y públicas, así como con otros actores sociales. Así, el documento de Correa (1963: 262) sostenía:

Como universitarios colombianos, con conciencia generacional de nuestras responsabilidades y de la misión de la universidad, y prescindiendo con criterio patriótico de consideraciones partidistas, grupales, regionalistas, o de cualquier otra índole, y compenetrados en la búsqueda de una universidad colombiana que remedie sus fallas, que cumpla sus funciones genéricas en estrecha relación con su función social, para que induzca en cuanto esté a su alcance el proceso de desarrollo que el país necesita y para que sea un efectivo agente de cambio social: Decidimos: Unirnos para buscar las formas más adecuadas al objetivo de lograr una universidad pública (nacionalizada), democrática, autónoma para cumplir sus funciones genéricas y su función social, y universalista.

Por otra parte, existió una tensión entre la idea de construir una organización y un proyecto gremial o corporativo de los estudiantes y apostarle a un proyecto abiertamente político (Uribe, 1998: 575). De acuerdo con Lucio y Serrano (1992: 68), la tesis política dominó desde 1965, lo que coincide con la influencia de Camilo Torres y el giro insurreccional de la FUN. Empero, no se trataba de dos concepciones excluyentes; por el contrario, lo gremial y lo político se articulaban de distintas maneras de acuerdo a las estrategias y tácticas de las distintas organizaciones (reformistas y revolucionarias, por ejemplo). Así, en la práctica ambas dimensiones se confundían y en últimas la actitud de los universitarios era política aunque se declarase en primer término como gremial (Rodríguez, 1978: 77). El documento de la FUN presentado en el congreso de 1963 afirmaba:

...la lucha de los universitarios debe estar integrada en dos aspectos fundamentales e inseparables: el gremial y el político, en su más alta concepción. No se trata de lucha partidista, sino de enfrentamiento contra las obsoletas estructuras actuales (FUN, 1963: 264).

En fin, la identidad estudiantil tenía una vocación popular, por llamarlo de alguna manera, que implicaba articular distintos sectores más allá de los universitarios. Por ejemplo, el documento de Correa (1963: 238) interpelaba así a otros sectores: "Este estudio, entonces, va dirigido a quienes no se lucran del estado actual del país, a quienes tienen sensibilidad social, a quienes no los amedrentan las ideas. Y que por suerte son los más".

\section{c. El proyecto}

Durante los sesenta el movimiento estudiantil retomó como proyecto universitario los postulados del Manifiesto de Córdoba (1918) que comprendía el cogobierno y la elección por voto universal y directo de las autoridades universitarias; la libertad de cátedra y de investigación; la autonomía universitaria; el concurso docente; la planeación universitaria y la investigación según las necesidades del país, y la gratuidad como forma de democratizar 
la educación (Hernández, 2007: 37). Esto se observa en los documentos de la UNEC y de la FUN. El artículo 5, parágrafo 2, de los estatutos de la UNEC declaraba como propósito de la organización:

Propender por la autonomía académica, administrativa y financiera de la universidad; por la mayor intervención del estudiantado en la dirección de la misma; auspiciar las reformas indispensables de los sistemas vigentes en la educación de tal forma que facilite la extirpación del analfabetismo; la realización de la enseñanza primaria, la implantación y realización de la enseñanza secundaria obligatoria y gratuita, y al mismo tiempo se destine el presupuesto adecuado para ello (UNEC, 1958: 224).

En el mismo sentido, en los documentos aprobados por la FUN en el Congreso Universitario de noviembre de 1963 en Bogotá, se decía que la organización "luchará por una reforma universitaria que comprenda la planeación integral de la universidad colombiana y una transformación de sus estructuras con miras a conseguir una universidad nacionalizada, democrática, universalista y autónoma para cumplir sus funciones genéricas y su función social" (FUN, 1963: 263). Así, en el discurso de los estudiantes estaba muy presente el papel que como tal deberían desempeñar en la sociedad. El artículo 5 de los estatutos de la UNEC declaraba: "Son fines de la UNEC: luchar por el mejoramiento intelectual, material y moral de sus afiliados y contribuir a la solución de los problemas nacionales" (UNEC: 1958: 224). Más claramente se planteaba en los documentos de la FUN:

La FUN considera que la universidad, como institución dinámica, debe permanecer en estrecho nexo con la realidad nacional. Cuando la universidad se aísla de los problemas nacionales, no los estudia ni debate en sus aulas, ni participa en su solución palpando su realidad, no cumple su función social y puede convertirse en un ser extraño y hasta en un verdadero estorbo a las transformaciones nacionales. Por eso, la FUN buscará integrar la universidad al estudio y solución de la problemática nacional.

La universidad es un reflejo de la sociedad en la cual vive. Es una creación de ella. El adelanto de la universidad será posible en la medida en que se produzcan transformaciones progresistas de la sociedad mayor. Y una verdadera transformación de las estructuras universitarias solo se producirá cuando se realicen las profundas transformaciones económicas, sociales y políticas que nuestro país subdesarrollado requiere (FUN, 1963: 264).

Sin embargo, como antes se mencionó, el problema de la universidad se enmarcaba en el más amplio del subdesarrollo. Por tanto, la solución de los problemas universitarios pasaba por resolver el problema del subdesarrollo:

...la universidad está substancialmente limitada para garantizar el acceso a la educación superior en base al mérito respectivo y no a la posición económica, debido al subdesarrollo del país. O sea que en tanto no se inicie un proceso acelerado de desarrollo, en tanto no se eleve sustancialmente el ingreso y el nivel de vida de los mayores sectores de la población, en tanto no se rompan las actuales estructuras en cuanto tienen de feudales o semi-feudales, en tanto no se ponga fin a la explotación 
imperialista a nuestro país, la universidad estará fuera del alcance de ellos, pues ni siquiera les es posible cursar la primaria por las causas anotadas" (Correa, 1963: 256).

En este marco, por lo menos en la interpretación de la FUN, la universidad tenía mucho que hacer, aunque no pudiese resolver de fondo los problemas del subdesarrollo:

De lo considerado anteriormente, deducimos en forma lógica que la universidad, en su condición de institución, no puede sacar al país del subdesarrollo, pues sus causas se localizan en el plano económico, político y social. Pero sí puede contribuir, aún en forma apreciable y por lo demás absolutamente necesaria, para realizar o inducir un proceso acelerado de desarrollo. Ello a través del cumplimiento de lo que llamamos su función social y que consiste en la orientación de su política docente y académica a la investigación y al descubrimiento de las causas reales del subdesarrollo y a la prospectación de las soluciones para salir de él. Es decir, enfrentar e problema en todos sus órdenes" (Correa, 1963: 257).

Cumplir la "función social" implicaba reformas tendientes a una universidad autónoma: "auto-dirigida, libre de presiones, interferencias o imposiciones de grupos económicos, religiosos, políticos o de otra índole" (Correa, 1963: 261). Se trataba de que la universidad fuese democratizada para que permitiera el acceso a las clases populares. La política universitaria debía orientarse a la solución de las necesidades del país, para lo cual era urgente aumentar los recursos estatales, particularmente en investigación y docencia. Esto necesariamente pasaba por la "nacionalización" de la universidad, que atacaría dos flancos. De una parte, el crecimiento y predominio de la educación privada, pues se reclamaba la financiación estatal a las universidades y no sólo por la vía de créditos o subsidios a la demanda. Por otra, la disputa en contra del imperialismo representado en las fundaciones y agencias norteamericanas. La responsabilidad del Estado, sin embargo, no debería traducirse en una vulneración de la autonomía universitaria y el cogobierno. "A más de pública (nacionalizada), democrática y autónoma, como secuela de sus funciones genéricas la universidad debe ser "universalista", abierta a todas las corrientes del pensamiento humano" (Correa, 1963: 261). En fin, este proyecto de universidad podría resumirse en el concepto de universidad popular:

El logro de una universidad verdaderamente popular implica no solamente que sus puertas estén abiertas a todas las capas de la sociedad y que se incremente el número de residencias, becas, etc. -bienestar estudiantil- para los estudiantes carentes de recursos económicos, sino también que su orientación esté dirigida al servicio de los intereses de nuestro pueblo. Esto significa que la universidad se convierta en la avanzada intelectual y cultural de las clases trabajadoras.

Y si se tiene en cuenta que toda la problemática nacional, y por consiguiente la universitaria, es consecuencia de una situación de subdesarrollo económico que resulta y se mantiene por la dependencia económica de los intereses extranjeros, especialmente de los grandes monopolios internacionales, que tienen a estos países como proveedores de materias primas baratas y como mercado de artículos elaborados caros, la lucha de los universitarios debe estar dirigida contra tales cadenas: buscar la independencia económica y política como única manera de afirmar la auténtica 
soberanía nacional -y de abrir con ello verdaderos cauces a la realización personal y generacional-, constituye misión ineludible para los universitarios colombianos.

Igualmente, si consideramos que la población colombiana es en su mayoría rural, y que este sector es el más depauperado de la nación, es deber de la universidad vincularse a las luchas por la transformación del sistema de tenencia de la tierra, buscando su distribución equitativa y su utilización planeada y racional en beneficio directo de las mayorías, con miras a suprimir este decisivo factor de atraso del país" (FUN, 1963: 264-265).

\section{Corolario}

Los años sesenta en Colombia estuvieron caracterizados por el auge de la protesta universitaria en el marco de la discusión sobre la reforma universitaria. Este fenómeno tuvo lugar en un contexto poco propicio para la protesta social, en la medida en que en la época existía un sistema político excluyente y represivo que aumentaba sus costos. Por consiguiente, la influencia de la izquierda sobre el estudiantado constituye un factor decisivo para comprender el auge de la protesta.

En un contexto nacional adverso, fueron las organizaciones de izquierda, impregnadas de la transformación global que en esos años se presentaba, los factores principales que permitieron la articulación del estudiantado en torno a demandas a favor de la autonomía universitaria, el cogobierno y la adaptación de la educación superior a las necesidades de un país subdesarrollado y de su pueblo, más que de agentes imperialistas.

Los elevados costos para la acción colectiva producto de la represión gubernamental quedaron reducidos frente a los proyectos políticos de largo plazo que se formuló la izquierda de aquellos años. En fin, las distintas expresiones de esta corriente política contribuyeron con una infraestructura organizativa, una experiencia política y unos marcos de acción colectiva producto de los cuales hubo una articulación entre los estudiantes universitarios, y entre ellos y otros sectores sociales, en función de la movilización social.

Paradójicamente, como se encargaría de mostrarlo el ciclo de protestas estudiantiles de 1971, la influencia de la izquierda no sólo explicaría por qué el estudiantado de los sesenta se involucró masivamente en protestas y proyectos de transformación social, sino también cuáles fueron los límites de ese compromiso. Uno de esos límites, tal vez el más importante, estaría constituido por las irascibles disputas internas entre las distintas corrientes de la izquierda, que no pocas veces habrían de obstaculizar los desarrollos de las luchas universitarias. 


\section{Referencias}

Acevedo, Á. (2004). Modernización, conflicto y violencia en la universidad en Colombia. AUDESA (1953-1984). Bucaramanga: UIS.

Acevedo, Á. y Gómez, F. (2000). "Conflicto y violencia en la universidad en Colombia. El proyecto modernizador y el movimiento estudiantil universitario en Santander, 1953-1980", Reflexión política, 2(4).

Acevedo, Á. y González, D. (2011a) "Movilización y protesta estudiantil en Colombia (1971). Una lectura desde la organización gremial por el cogobierno universitario y la memoria de protagonistas y testigos", Anuario de Historia Regional y de las Fronteras, 16, pp. 221-242.

Acevedo, Á y González, D. (2011b) "Protesta y movilización estudiantil, 1964. Memoria de una marcha en la Universidad Industrial de Santander", Anuario Colombiano de Historia Social y de la Cultura, 38(2), pp. 255-276.

Acevedo, Á. y Samacá, G. (2011). "Revolución y cultura en América Latina: el movimiento estudiantil como objeto de estudio en la historiografía colombiana y continental", Memoria y sociedad, 15(31), pp. 104-119.

Acevedo, Á. y Samacá, G. (2013). "Juventudes universitarias de izquierda en Colombia en 1971: un acercamiento a sus discursos ideológicos". Historia Caribe, VIII (22), pp. 195-229.

Acosta, A. (1998). "Entre consignas y pancartas". En Uribe, M. (coord.), Universidad de Antioquia: historia y presencia. Medellín: UdeA, pp. 588-589.

Aguilera, A. (2011). Subjetividades políticas y movimientos sociales en defensa de la universidad pública: Colombia-México. Tesis de doctorado en Estudios latinoamericanos UNAM.

Archila, M. (1997). "El Frente Nacional: una historia de enemistad social", en Anuario Colombiano de Historia Social y de la Cultura, 24.

Archila, M. (2003). Idas y venidas, vueltas y revueltas. Protestas sociales en Colombia 1958-1990. Bogotá: Cinep.

Archila, M. (2012). "El movimiento estudiantil en Colombia. Una mirada histórica", OSAL, 31, pp. 71-103.

Archila, M. y Cote, J. (2009). "Auge, crisis y reconstrucción de las izquierdas colombianas (19582006)”, en VVAA, Una historia inconclusa. Izquierdas políticas y sociales en Colombia. Bogotá: Cinep, pp. 55-90.

Beltrán, W. (2002), "Del dogmatismo católico al dogmatismo de izquierda. El ambiente político en la Universidad Nacional en los años 60 y 70", en Revista Colombiana de Sociología, Vol VII, No. 2, pp. 155-178.

Correa, F. "Introducción al estudio de la universidad colombiana. Ponencia $2^{\circ}$ y $3^{\circ}$ Congreso Nacional Estudiantil. Consejo Superior Estudiantil de la Universidad Nacional". Reproducido en Ruiz, 2002: pp. 237-262.

Cote, J. (2014). “¿Quiénes son los estudiantes? Aspectos teóricos sobre las perspectivas de análisis del movimiento estudiantil en los años sesenta y setenta". En Zuleta, M. y Urrego, M. (eds.), Izquierdas: definiciones, movimientos y proyectos en Colombia y América Latina. Bogotá: Universidad Central, pp. 103-114.

Díaz, J. (2010). "Jueventud, nueva izquierda y revolución en Colombia: lo avatares políticos de Antonio Larrota González", Controversia, 194, pp. 265-291.

Federación Universitaria Nacional (1963). "Documentos aprobados por el Congreso Nacional Universitario. Noviembre-Bogotá”. Reproducido en: Ruiz, 2002: pp. 263-269.

Hernández, I. (2007). "El programa mínimo de los estudiantes colombianos. Movimiento estudiantil universitario de 1971 por la universidad. Todo un país", Revista Historia de la educación colombiana, 10, 2007, pp. 29-57. 
Jiménez, A. (2001). "Consolidación, auge y crisis del Movimiento estudiantil en la Universidad Pedagógica Nacional: 1957-1974”, Anuario Colombiano de Historia Social y de la Cultura, 28, 5586.

Latorre, M. (1980). "La universidad de espaldas al sistema", en Política y elecciones. Bogotá: Universidad de los Andes, pp. 39-68.

Le Bot, Y. (1979). Educación e ideología en Colombia. Medellín: La Carreta.

Leal, F. (1984). "La participación política de la juventud universitaria como expresión de clase", en Cárdenas, M. y Díaz, A. (eds.), Juventud y Política en Colombia. Bogotá: FESCOL-Instituto SER, pp. 155-203.

Leal, F. y Dávila, A. (1991) Clientelismo. El sistema político y su expresión regional. Bogotá: TMIEPRI.

Lucio R. y Serrano M. (1992). La educación superior. Tendencias y políticas estatales. Bogotá: Universidad Nacional de Colombia.

Medina, M (1984). La protesta urbana en Colombia en el siglo XX. Bogotá: Aurora.

McAdam, D. (1999). "Orígenes terminológicos, problemas actuales, futuras líneas de investigación”. En McAdam, D., McCarthy, J. y Zald., M. (ed.), Movimientos sociales: perspectivas comparadas. Oportunidades políticas, estructuras de movilización y marcos interpretativos culturales. Madrid: Itsmo.

McAdam, D., McCarthy, J. y Zald, M. (1999). Movimientos sociales: perspectivas comparadas. Oportunidades políticas, estructuras de movilización y marcos interpretativos culturales. Madrid: Itsmo.

McAdam, D., Tarrow, S. y T. Ch. (2005). Dinámica de la contienda política. Barcelona: Hacer.

McCarthy, D. (1999). "Adoptar, adaptar e inventar límites y oportunidades". En McAdam, D., McCarthy, J. y Zald, M. (eds.), Movimientos sociales: perspectivas comparadas. Oportunidades políticas, estructuras de movilización y marcos interpretativos culturales. Madrid, Itsmo, pp. 205220.

Molina, G. (1978) "Universidad estatal y universidad privada”, en VVAA, ¿Universidad oficial o universidad privada? Bases para una política universitaria. Bogotá: TM, pp. 11-66.

Múnera, L. (1998). Rupturas y continuidades. Poder y movimiento popular en Colombia 19681988. Bogotá: Universidad Nacional de Colombia-CEREC.

Ordóñez, L. (2007). Universidad del Valle 60 años 1945-2005. Atando cabos en clave de memoria. Cali: Univalle.

Pardo, M. y Urrego, M. (2003). "El movimiento estudiantil de 1971 en Colombia. Ponencia presentada por los autores en el Primer Congreso Internacional sobre Historia de las Universidades de América y Europa, realizado del 10 al 12 de julio de 2003 en la Universidad de Córdoba Argentina. Igualmente, en el $51^{\circ}$ Congreso Internacional de Americanistas, realizado entre el 14 y el 18 de julio de 2003 en Santiago de Chile.

Pécaut, D. (1989) Crónica de dos décadas de política colombiana. Bogotá: Siglo XXI.

Puyana, A. y Serrano, M. (2000). Reforma o inercia en la universidad latinoamericana. Bogotá: IEPRI-TM.

Rivas, A. (1998). "El análisis de los marcos: una metodología para el estudio de los movimientos sociales”. En Ibarra, P. y Tejerina, B. (eds.), Los movimientos sociales. Transformaciones políticas y cambio cultural. Madrid: Trotta, pp. 181-215.

Rodríguez, J. (1978). "El Estado y la universidad en conflicto”, en VVAA, ¿Universidad oficial o universidad privada? Bases para una política universitaria. Bogotá: TM.

Ruch, D. (1999). "El impacto de los contextos nacionales sobre la estructura de los movimientos sociales: un estudio comparado transnacional y entre movimientos". En McAdam, D., McCarthy, J. 
y Zald., M. (ed.), Movimientos sociales: perspectivas comparadas. Oportunidades políticas, estructuras de movilización y marcos interpretativos culturales. Madrid: Itsmo. pp. 262-287.

Ruíz, J. (1998). "Mis vivencias como estudiante universitario". En Uribe, M. (coord.), Universidad de Antioquia: historia y presencia. Medellín: UdeA, pp. 584-588.

Ruiz, M. (2002). Sueños y realidades. Procesos de organización estudiantil 1954-1966. Bogotá: Universidad Nacional de Colombia.

Snow, D. y Benford, R. (1992). "Master frames and cycles of protest". En Morris, A.. y McClury, C. (eds.), Frontiers in social movement theory. New Haven and London: Yale University Press, pp. 133-155.

Tarrow, S. (1997). El poder en movimiento. Los movimientos sociales, la acción colectiva y la política. Madrid: Alianza.

UNEC (1958) "Estatutos de la Unión Nacional de Estudiantes Colombianos". Reproducido en Ruiz, 2002: pp. 223-230.

Uribe, M. (coord.) (1998). Universidad de Antioquia: historia y presencia. Medellín: UdeA

Valenzuela, S. (2012). "Transición por redemocratización. El Frente Nacional colombiano en una reflexión teórica y comparativa". En Carlos Caballero Argáez, Mónica Pachón Buitrago y Eduardo Posada Carbó (comps.), Cincuenta años de regreso a la democracia. Bogotá, Universidad de Los Andes, 2012, pp.

Vargas, L. (1996). Expresiones políticas del movimiento estudiantil AUDESA, 1960-1980. Bucaramanga: UIS.

Villamil, E. (2010). "Rompiendo esquemas: discusiones, consignas y tropeles del estudiantado universitario en Colombia en 1971", Controversia, 194, pp. 233- 263.

VVAA. (1971). Crisis universitaria colombiana 1971. Itinerario y documentos. Medellín: Ediciones El Tigre de Papel.

VVAA. (2001). Historia del movimiento estudiantil de la Universidad Libre. Bogotá: Universidad Libre.

Zald, M. (1999). "Cultura, ideología y creación de marcos estratégicos". En McAdam, D. McCarthy, J. y Zald, M. (eds), Movimientos sociales: perspectivas comparadas. Oportunidades políticas, estructuras de movilización y marcos interpretativos culturales. Madrid: Itsmo, pp. 369388. 